\title{
Short-stem reconstruction for megaendoprostheses in case of an ultrashort proximal femur
}

Ralf Dieckmann*, Marcel-Philipp Henrichs, Georg Gosheger, Steffen Höll, Jendrik Hardes and Arne Streitbürger

\begin{abstract}
Background: Tumors of the distal femur and diaphysis with proximal metaphyseal extension into the femur present a challenge for limb salvage. The conventional treatment consists of limb salvage with total femur replacement. This case study aims to present preliminary results and experience with short-stem reconstruction, focusing on the mechanical stability of the procedure.

Methods: Sixteen short stems were implanted in 15 patients. The patients' mean age was 33,3 years (range 11-73). In 10 patients, the stem was used for distal femur reconstruction, in one patient for diaphyseal reconstruction, and in four for a stump lengthening procedure. All of the patients had a primary sarcoma in their history. The mean follow-up period was 37 months (range 5-95 months). The clinical and functional follow-up data were analyzed.

Results: Ten patients (67\%) were still alive at the time of evaluation. Three complications associated with the stem were noted. In one case, there was aseptic loosening after 58 months; in another, aseptic loosening occurred because the diameter of the stem had initially been too small; and in one case, there was breakage of the fixation screw, without any clinical symptoms. The average Musculoskeletal Tumor Society score for all patients was 23 (range 9-28). The mean result for the distal femur replacement was 24 (range 22-28). None of the surviving patients with distal femur replacements needed any crutches or had a Trendelenburg limp. Both living patients who underwent a stump lengthening procedure were able to walk with an exoprosthesis.

Conclusions: The short stem is a good solution that can prevent or delay proximal femur resection in patients with tumors extending into the proximal metaphyseal femur. Additional risks of proximal femur resection, such as dislocation, opening of another oncological compartment, Trendelenburg limp, and chondrolysis can be avoided.
\end{abstract}

Keywords: Distal femur replacement, Tumor, Aseptic loosening, Limb salvage, Short stem

\section{Background}

Tumors of the distal femur and diaphysis with proximal metaphyseal extension into the femur present a challenge for limb salvage. The conventional treatment consists of limb salvage with total femur replacement [1-6].

The disadvantage of total femur resection is that the hip joint has to be resected. This leads to disruption of all the muscles in the proximal femur and leads to a poorer functional outcome, including Trendelenburg limp, in comparison with distal femur replacement $[1,7,8]$. In addition to

\footnotetext{
*Correspondence: Ralf.Dieckmann@ukmuenster.de

Department of Orthopedics and Tumor Orthopedics, University of Münster, Albert-Schweitzer-Campus 1, A1, 48149 Münster, Germany
}

the problems resulting from distal femur resection, a risk of luxation of the hip is also present $[4,8]$.

To delay or avoid resection of the hip joint in patients with an ultrashort proximal femur shaft, we use a short stem called the "Buxtehude stem" (Implantcast Ltd., Buxtehude, Germany). We use this stem in cases of distal femur resection and for diaphyseal implants when there is an ultrashort proximal femur shaft. We also use it for the stump lengthening procedure. In our clinic the indication for this stem is a proximal femur shaft with $110 \mathrm{~mm}$ or less in young patients. Another indication is a bad bone stock in case of revision. In one special case we used a stem length of $130 \mathrm{~mm}$ (Figures 1). 


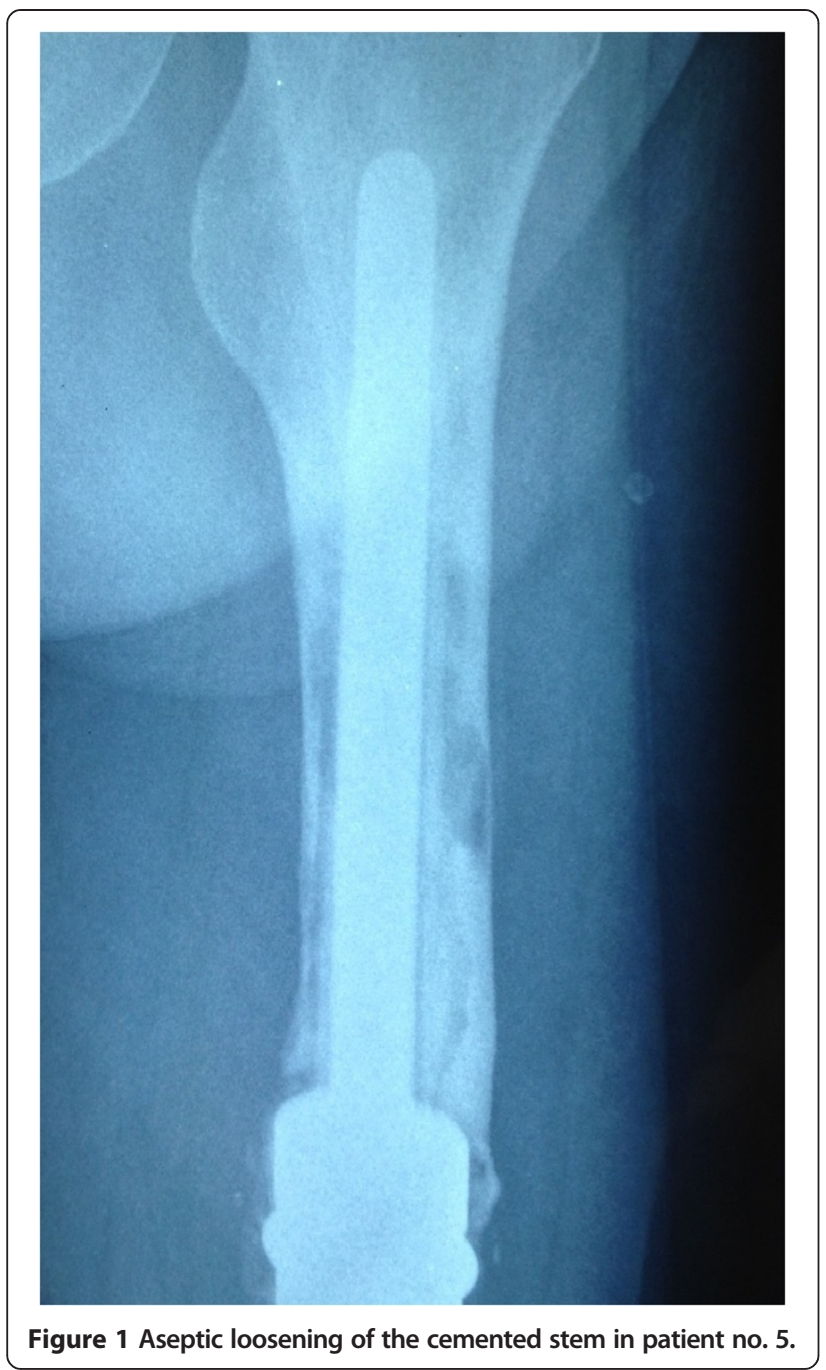

The aim of this case study is to present preliminary results and experience with this short stem, focusing on the mechanical stability of the procedure.

\section{Methods}

The "Buxtehude stem" is custom made and has to be ordered at least 4 weeks before the planned operation. There must be at least $40 \mathrm{~mm}$ of the femur left. The stem fixation technique is based on three principles: Firstly, the rib profile of the stem is for fixation in spongy bone. Secondly, the top (diameter $10 \mathrm{~mm} /$ length $10 \mathrm{~mm}$ ) is fixed in the fossa piriformis, therefore the stem length should be at least $5 \mathrm{~mm}$ longer than the remaining femur. Thirdly, screw fixation in the femoral neck avoids rotation and enhances primary rotation stability. In the past we used a simple $6,5 \mathrm{~mm}$ spongiosa screw for locking. After breakage of the screw in patient No 2 we changed to a $8 \mathrm{~mm}$ locking screw (Implantcast ltd., Buxtehude). After this methological change no further problems occurred. A coating with hydroxylapatid is possible, but it takes at least 2 weeks longer to produce this stem. Especially in tumour cases the timing with chemotherapy is necessary. Therefore we abandoned of coating in the past.

We had an ethics approval of the local ethic committee of the University of Münster (2014-040-f-N). Every patient or parents of children were informed about the study and agreed to publish their data. A consent statement was signed.

A total of 16 short stems were implanted in 15 patients between 2003 and 2012. The patients' mean age was 33,3 years (range 11-73 years). There were six female and 9 male patients. The stem was used for distal femur reconstruction in 10 patients, for diaphyseal reconstruction in one, and for a stump lengthening procedure in four (Figures 2, 3 and 4). For planning the stem a x-ray with a measuring guide on the bone level was performed. The mean follow-up period was 37 months (range 5-95 months).

All of the patients had a primary sarcoma in their history. The indication for using the short stem was a primary tumor in seven patients, aseptic loosening of a distal femur replacement in five, and local recurrence or intralesional resection in four (Table 1). Stump lengthening procedures were performed in the four patients with local recurrence or intralesional resection (Table 2). The Enneking stage at the time of surgery was IIb in nine patients and IIIb in six (Table 1).

For the clinical follow-up, radiographs from the regular follow-up were analyzed and the patients' general practitioners were contacted for further information regarding the stage of disease, or in case of death its cause and date. The surviving patients were contacted to obtain information from a questionnaire assessing current symptoms, occupation, and functional evaluation.

Functional evaluation was carried out in nine patients using the Musculoskeletal Tumor Society (MSTS) score [9]. Five patients had died of disease and one patient did not want to response to the questionnaire.

\section{Results}

\section{Oncological data}

At the time of the evaluation, ten patients (67\%) were still alive. Five patients with lung metastases had died. None of the patients developed any local recurrences after resection of the primary sarcoma.

\section{Surgical data}

The short stem was used for distal femur replacement in 10 cases, in one case for diaphyseal reconstruction, and in four cases for a stump lengthening procedure (Table 2). The mean stem length was $77 \mathrm{~mm}$ (range 45-130 $\mathrm{mm}$ ) and the mean diameter of the stem was $21 \mathrm{~mm}$ (range $18-25 \mathrm{~mm})$. The uncemented stem was fixed into the femoral neck with a screw in all cases. 


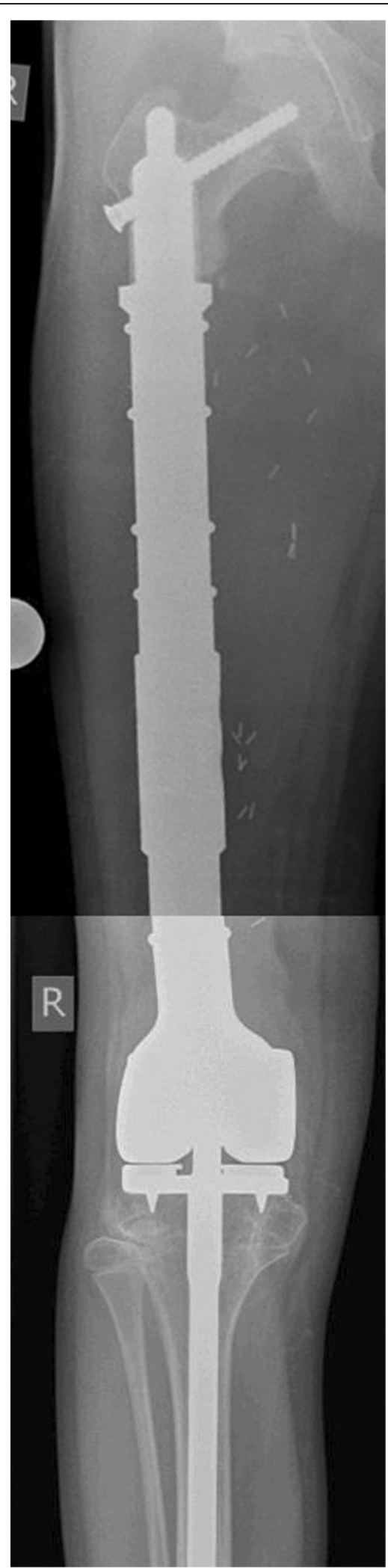

Figure 2 Patient no. 8. Distal femur replacement with short stem and polished tibia stem.

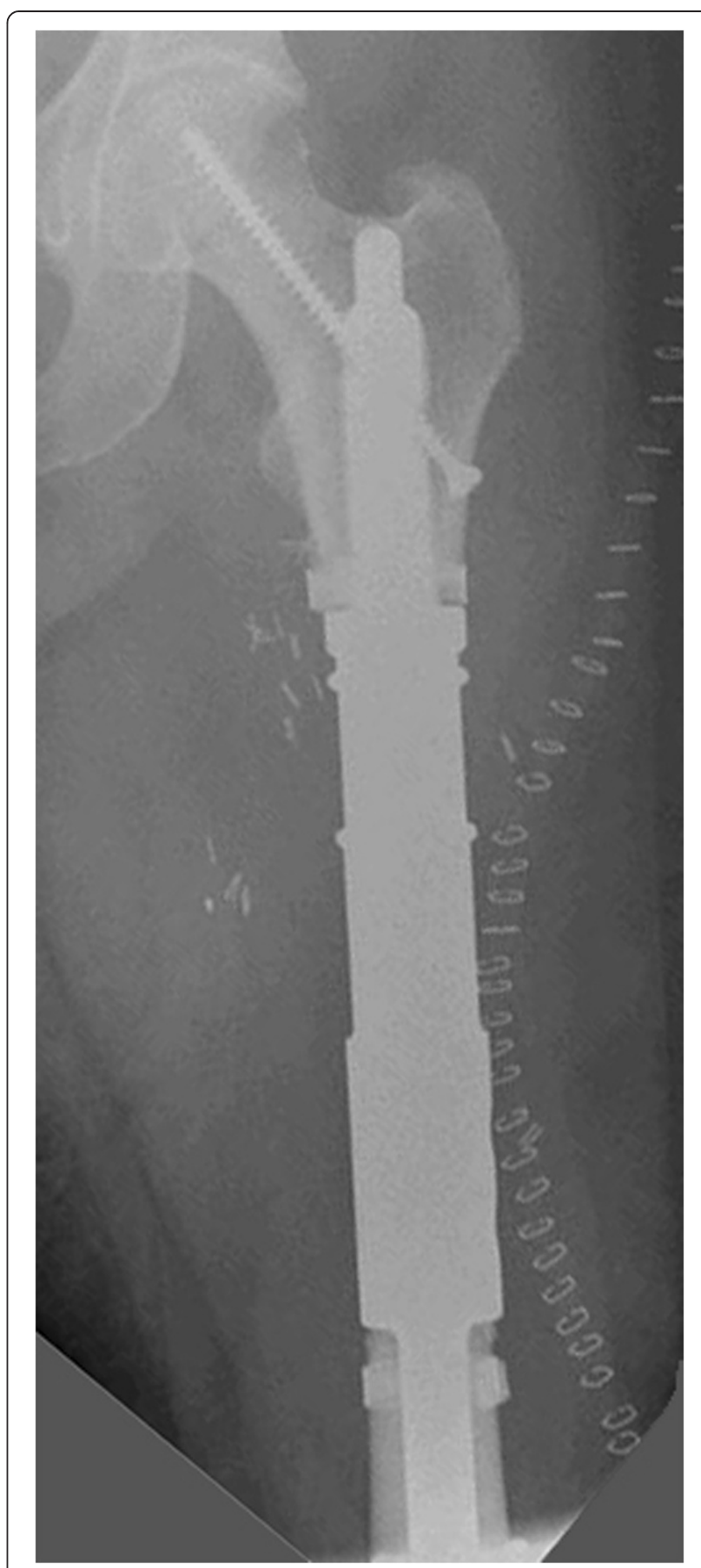

Figure 3 Patient no. 11. Diaphyseal reconstruction

\section{Complications}

Three complications associated with the stem were observed, as well as four complications independent of the fixation technique (Table 2).

A screw fracture occurred in patient no. 2, with no therapeutic consequences. The patient also had an osteoporotic tibial fracture. He had already had a lung metastasis at the 


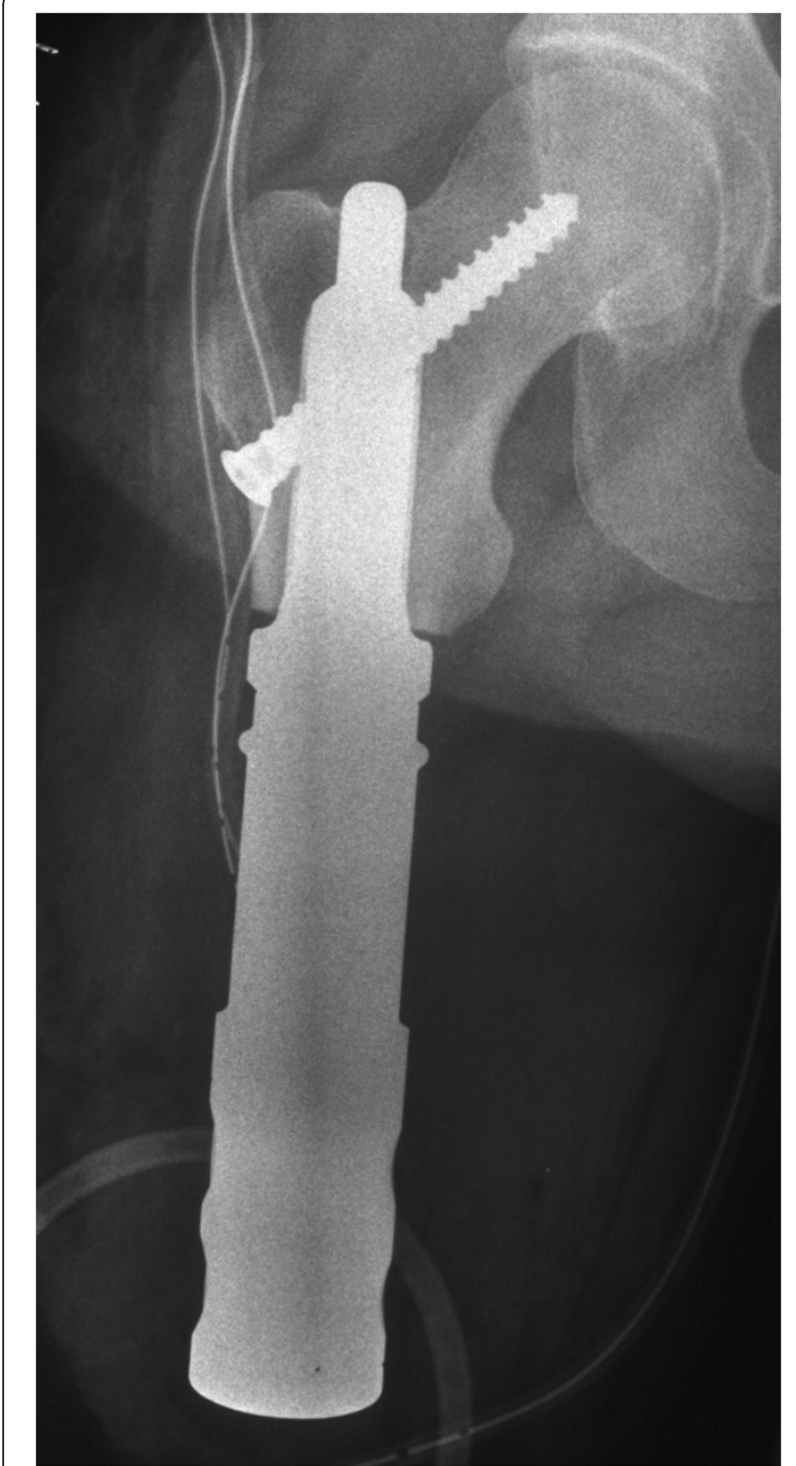

Figure 4 Patient no. 15. Stump lengthening procedure.

time of primary surgery, and died 48 months after implantation of the stem.

Patient no. 5 had aseptic loosening after 58 months and needed to be switched to a total femur replacement (Figures 5). The patient had not had any problems before the aseptic loosening.

Early aseptic loosening occurred after 14 months in patient no. 8. Retrospectively, the reason was found to be that a too small stem had been implanted during the initial operation. After revision with a thicker stem, the patient became free of pain and had a good functional result after 22 months.

\section{Functional results}

Due to the small number of patients and the different indications for implantation of the stem, the results are limited. It was possible to evaluate the MSTS score in six patients with distal femur replacement, in one with diaphyseal reconstruction, and in two who underwent stump lengthening procedures. The average MSTS score for all patients was 23 (range 9-28). Patient no. 15, with a stump lengthening procedure, had the poorest result. The mean result for distal femur replacement was 24 (range 22-28). None of the surviving patients with distal femur replacement needed crutches or had a Trendelenburg limp. Both living patients who had undergone a stump lengthening procedure were able to walk with an exoprosthesis, and one of them still intermittently needed crutches. Both patients who died had an interim exoprosthesis. They were in bad general condition and not able to walk, because of the oncological progression with lung metastasis.

\section{Discussion}

Sarcomas often occur in young patients, as in the present study. Limb salvage is nowadays possible in most cases [8]. Because of the patients' young age, it is necessary to use an anticipatory prosthetic system. Due to the good oncological survival rates, revision surgery of the prostheses is unavoidable [10,11]. Distal and diaphyseal tumors with a long proximal femoral extension are often an indication for total femur replacement [1-6].

The complication rates with total femur replacement are high $[1,2,5,8]$, and the functional outcome is poorer than with distal femur replacement $[8,12]$. The patients often need crutches or other aids to walk [1]. A specific problem with total femur replacement is dislocation, which occurs in up to $12 \%$ of cases $[1,2,5,8]$ and Trendelenburg limping $[8,12]$. We have increasingly used a bipolar head or tripolar cup, which may help to reduce this high dislocation rate. Furthermore, when a bipolar head is used painfull chondrolysis can occure as a long term problem [11]. Preserving the hip joint can avoid all these problems. In the present study the surviving patients with distal femur replacement had no need of crutches and no risk of dislocation.

From the oncological point of view, proximal femur resection leads to a further problem, as an additional compartment is opened. If there is an intralesional resection or local recurrence, or if infection occurs, the hip joint may be contaminated. To ensure wide margins in case of local recurrence, a hemipelvectomy may be necessary. There were no cases of local recurrence in the present study, but local recurrence rates of up to $10 \%$ have been reported in patients with total femur replacement $[2,3]$.

Another cementless short stem solution with encouraging results is the Compress ${ }^{\circ}$ implant (Fa. Biomet, Warsaw, USA). The early aseptic loosening rate varies from $3,8 \%$ up to $14 \%$ [13-17], but the results are limited 
Table 1 Indications and stage of disease

\begin{tabular}{|c|c|c|c|c|c|c|}
\hline Patient no. & Age & Sex & Primary malignancy & Metastasis & Enneking stage & Indication \\
\hline 1 & 11 & $\mathrm{~F}$ & Ewing sarcoma & Lung & $I I I b$ & Primary sarcoma \\
\hline 2 & 20 & M & Osteosarcoma & Lung & $\| l \mathrm{~b}$ & Primary sarcoma \\
\hline 3 & 23 & M & Osteosarcoma & 0 & $\| b$ & Aseptic loosening \\
\hline 4 & 31 & M & Osteosarcoma & 0 & $\| \mathrm{b}$ & Aseptic loosening \\
\hline 5 & 27 & M & Osteosarcoma & 0 & $\| \mathrm{b}$ & Aseptic loosening \\
\hline 6 & 36 & M & Osteosarcoma & 0 & $\| b$ & Aseptic loosening \\
\hline 7 & 26 & M & Osteosarcoma & Lung & $\| l \mid b$ & Primary sarcoma \\
\hline $8 a$ & 12 & M & Ewing sarcoma & 0 & $\| b$ & Primary sarcoma \\
\hline $8 b$ & 13 & M & Ewing sarcoma & 0 & & Aseptic loosening \\
\hline 9 & 20 & $\mathrm{~F}$ & Ewing sarcoma & 0 & $\| b$ & Primary sarcoma \\
\hline 10 & 55 & M & Chondrosarcoma & 0 & $\| \mathrm{b}$ & Primary sarcoma \\
\hline 11 & 60 & $\mathrm{~F}$ & Myxofibrosarcoma & 0 & $\| b$ & Primary sarcoma \\
\hline 12 & 49 & M & Chondrosarcoma & Lung & $\| l \mathrm{~b}$ & Local recurrence \\
\hline 13 & 25 & $\mathrm{~F}$ & Osteosarcoma & Lung & $\| l \mid b$ & Local recurrence \\
\hline 14 & 73 & $\mathrm{~F}$ & Osteosarcoma & Lung & $\| l l b$ & Intralesional resection \\
\hline 15 & 32 & $\mathrm{~F}$ & Osteosarcoma & 0 & $\| b$ & Local recurrence \\
\hline
\end{tabular}

by population size, heterogenic population and followup duration. The advantage of this system is that the compressive osteointegration avoids stress-shielding and save bone-stock. The standard intramedullary implant is $80 \mathrm{~mm}$ and was used in most of the studies [13-17]. Indeed an ultrashort reconstruction with $46 \mathrm{~mm}$ is possible.
However, in the existing studies it is not mentioned how often this short reconstruction is used. Furthermore there is no example where a Compress $^{\oplus}$ implant was used in case of an ultrashort proximal femur [13-17].

Cannon et al. used a cemented approach for fixation of short stems [18]. They used a $90^{\circ}$ cross-pin fixation for

Table 2 Results for patients with short-stem reconstruction

\begin{tabular}{|c|c|c|c|c|c|c|c|c|}
\hline \multirow[t]{2}{*}{ Patient no. } & \multirow{2}{*}{$\begin{array}{l}\text { Oncological } \\
\text { status }\end{array}$} & \multirow{2}{*}{$\begin{array}{l}\text { Follow-up } \\
\text { (months) }\end{array}$} & \multirow[t]{2}{*}{ Surgery } & \multicolumn{2}{|c|}{ Stem } & \multicolumn{2}{|c|}{ Complications } & \multirow[t]{2}{*}{ MSTS } \\
\hline & & & & Diameter (mm) & Length (mm) & Associated with stem & General & \\
\hline 1 & DOD & 5 & DFR & 20 & 55 & - & & - \\
\hline 2 & DOD & 48 & DFR & 20 & 55 & Screw fracture & Tibia fracture & - \\
\hline 3 & CDF & 95 & DFR & 20 & 130 & - & & - \\
\hline 4 & CDF & 72 & DFR & 20 & 100 & - & Disconnection of HMRS adapter & 24 \\
\hline 5 & CDF & 58 & DFR & 19 & 120 & Aseptic loosening & & 24 \\
\hline 6 & CDF & 35 & DFR & 19 & 120 & & Infection & 22 \\
\hline 7 & DOD & 18 & DFR & 24 & 95 & & & - \\
\hline $8 a$ & CDF & 14 & DFR & 18 & 45 & Aseptic loosening & & - \\
\hline $8 b$ & CDF & 22 & DFR & 25 & 45 & - & Limb length discrepancy $8 \mathrm{~cm}$ & 28 \\
\hline 9 & CDF & 33 & DFR & 21 & 55 & & & 24 \\
\hline 10 & CDF & 38 & DFR & 25 & 105 & - & & 25 \\
\hline 11 & CDF & 12 & ICS & 20 & 65 & - & & 28 \\
\hline 12 & AWD & 51 & SLP & 24 & 55 & - & & 24 \\
\hline 13 & DOD & 20 & SLP & 20 & 60 & - & & - \\
\hline 14 & DOD & 17 & SLP & 24 & 70 & - & & - \\
\hline 15 & AWD & 46 & SLP & 20 & 55 & - & & 9 \\
\hline
\end{tabular}




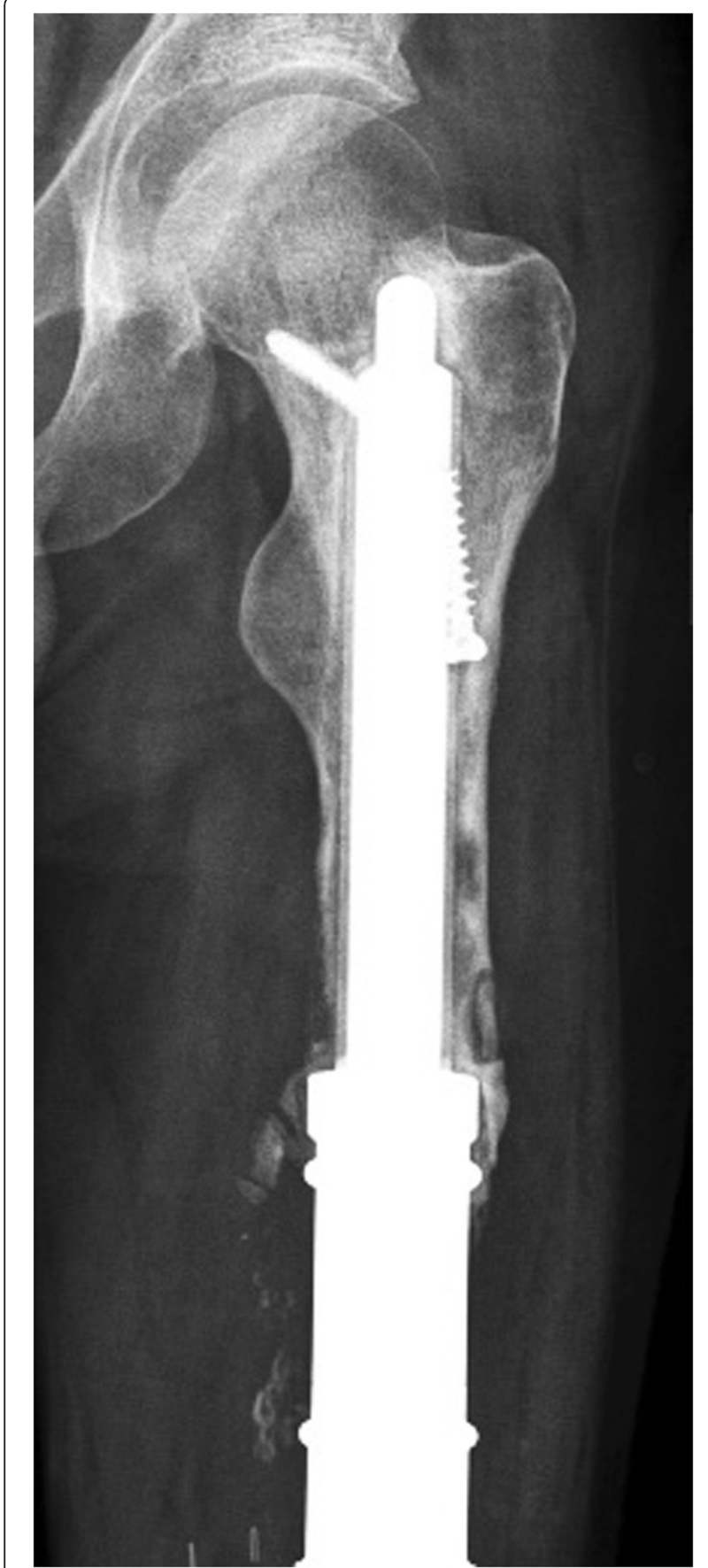

Figure 5 Patient no. 5: Aseptic loosening of the short stem in case of revision surgery.

diaphyseal segments and a $135^{\circ}$ cross-pin fixation for short proximal femoral segments. All these implants were custom made. In 14 cases a fixation with a $135^{\circ}$ in the proximal femur was done. A loosening was reported in one case.

In a meta-analysis the overall aseptic loosening rate of a distal femur replacement is 6,8\% [19]. The loosening rate of the standard MUTARS distal femur replacement with a cementless hydroxyl apatite coated stem and hexagonal shaft preparation is $7,7 \%$ [8]. In our small case series we have a loosening rate of $12,5 \%$. We think that one reason for this is the learning curve with the implant. Another reason is the short distance of anchoring the stem with sometimes bad quality of bone. As patient no. 5 in this study shows, using a short stem is not a permanent solution, but it may be able to delay the implantation of a total femur, with all its disadvantages, for several years. This is important particularly for young patients with high levels of physical activity.

Exceptional use of a short stem with a stump lengthening procedure is a very specialized indication. However, it is known that disarticulation of the hip joint and high-thigh amputation can lead to severe changes in function, mobility, and cosmetic appearance, and to considerable limitation of simple daily activities [20]. The two surviving patients in this study were able to walk using an exoprosthesis. Even the two patients, who died, were able to wear an interims exoprosthesis. Although the indication is rare, the approach can be useful in specific cases.

This study is limited by the small numbers of patients and short follow-up periods. Large numbers of patients in tumor surgery and homogeneous groups of patients with this type of tumor are rare [1,2]. Despite the small number of patients, the study showed that the mechanism of implantation of this short stem works, and it provided a proof of principle for this anchor system.

\section{Conclusion}

The Buxtehude short stem is a good solution that can avoid or delay proximal femur resection in patients with tumors extending into the proximal metaphyseal femur. Additional risks associated with proximal femur resection, such as dislocation, opening another oncological compartment, Trendelenburg limp, and chondrolysis can be avoided.

\section{Competing interests}

The authors declare that they have no competing interests.

\section{Authors' contributions}

$\mathrm{RD}$ participated in the design of the study, the literature search, the extraction of data and the methodological appraisal of the study. He performed the statistical analyses, led the interpretation of results, was writing and drafting the manuscripts. MPH, GG, SH, JH participated in the data collection. AS participated in the design of the study and the writing the manuscript. All authors read and approved the final manuscript.

\section{Acknowledgements}

We acknowledge support by Deutsche Forschungsgemeinschaft and Open Access Publication Fund of University of Muenster.

Received: 16 January 2014 Accepted: 23 May 2014

Published: 31 May 2014 


\section{References}

1. Ahmed AR: Total femur replacement. Arch Orthop Trauma Surg 2010, 130:171-176.

2. Kalra S, Abudu A, Murata H, Grimer RJ, Tillman RM, Carter SR: Total femur replacement: primary procedure for treatment of malignant tumours of the femur. Eur J Surg Oncol 2010, 36:378-383.

3. Marcove RC, Lewis MM, Rosen G, Huvos AG: Total femur and total knee replacement. A preliminary report. Clin Orthop Relat Res 1977, 126:147-152.

4. Pennekamp PH, Wirtz DC, Durr HR: Proximal and total femur replacement. Oper Orthop Traumatol 2012, 24:215-226.

5. Ruggieri P, Bosco G, Pala E, Errani C, Mercuri M: Local recurrence, survival and function after total femur resection and megaprosthetic reconstruction for bone sarcomas. Clin Orthop Relat Res 2010, 468:2860-2866.

6. Morris HG, Capanna R, Campanacci D, Del Ben M, Gasbarrini A: Modular endoprosthetic replacement after total resection of the femur for malignant tumour. Int Orthop 1994, 18:90-95.

7. Skaliczki G, Antal I, Kiss J, Szalay K, Skaliczki J, Szendroi M: Functional outcome and life quality after endoprosthetic reconstruction following malignant tumours around the knee. Int Orthop 2005, 29:174-178.

8. Gosheger G, Gebert C, Ahrens H, Streitbuerger A, Winkelmann W, Hardes J: Endoprosthetic reconstruction in 250 patients with sarcoma. Clin Orthop Relat Res 2006, 450:164-171.

9. Enneking WF, Dunham W, Gebhardt MC, Malawar M, Pritchard DJ: A system for the functional evaluation of reconstructive procedures after surgical treatment of tumors of the musculoskeletal system. Clin Orthop Relat Res 1993, 286:241-246.

10. Bernthal NM, Schwartz AJ, Oakes DA, Kabo JM, Eckardt JJ: How long do endoprosthetic reconstructions for proximal femoral tumors last? Clin Orthop Relat Res 2010, 468:2867-2874.

11. Donati D, Zavatta M, Gozzi E, Giacomini S, Campanacci L, Mercuri M: Modular prosthetic replacement of the proximal femur after resection of a bone tumour a long-term follow-up. J Bone Joint Surg (Br) 2001, 83:1156-1160

12. Jones KB, Griffin AM, Chandrasekar CR, Biau D, Babinet A, Deheshi B, Bell RS, Grimer RJ, Wunder JS, Ferguson PC: Patient-oriented functional results of total femoral endoprosthetic reconstruction following oncologic resection. J Surg Oncol 2011, 104:561-565.

13. Abrams GD, Gajendran VK, Mohler DG, Avedian RS: Surgical technique: methods for removing a Compress(R) compliant prestress implant. Clin Orthop Relat Res 2012, 470:1204-1212.

14. Bhangu AA, Kramer MJ, Grimer RJ, O'Donnell RJ: Early distal femoral endoprosthetic survival: cemented stems versus the Compress implant. Int Orthop 2006, 30:465-472.

15. Calvert GT, Cummings JE, Bowles AJ, Jones KB, Wurtz LD, Randall RL: A dual-center review of compressive osseointegration for fixation of massive endoprosthetics: 2- to 9-year followup. Clin Orthop Relat Res 2014, 472:822-829.

16. Kramer MJ, Tanner BJ, Horvai AE, O'Donnell RJ: Compressive osseointegration promotes viable bone at the endoprosthetic interface: retrieval study of compress implants. Int Orthop 2008, 32:567-571.

17. Pedtke AC, Wustrack RL, Fang AS, Grimer RJ, O'Donnell RJ: Aseptic failure: how does the Compress((R)) implant compare to cemented stems? Clin Orthop Relat Res 2012, 470:735-742.

18. Cannon CP, Eckardt JJ, Kabo JM, Ward WG Sr, Kelly CM, Wirganowicz PZ, Asavamongkolkul A, Nieves R, Eilber FR: Custom cross-pin fixation of 32 tumor endoprostheses stems. Clin Orthop Relat Res 2003, 417:285-292.

19. Henderson ER, Groundland JS, Pala E, Dennis JA, Wooten R, Cheong D, Windhager R, Kotz Rl, Mercuri M, Funovics PT, Hornicek FJ, Temple HT, Ruggieri $P$, Letson GD: Failure mode classification for tumor endoprostheses: retrospective review of five institutions and a literature review. J Bone Joint Surg Am 2011, 93:418-429.

20. Yari P, Dijkstra PU, Geertzen JH: Functional outcome of hip disarticulation and hemipelvectomy: a cross-sectional national descriptive study in the Netherlands. Clin Rehabil 2008, 22:1127-1133.

doi:10.1186/1471-2474-15-190

Cite this article as: Dieckmann et al:: Short-stem reconstruction for megaendoprostheses in case of an ultrashort proximal femur. BMC Musculoskeletal Disorders 2014 15:190.

\section{Submit your next manuscript to BioMed Central and take full advantage of:}

- Convenient online submission

- Thorough peer review

- No space constraints or color figure charges

- Immediate publication on acceptance

- Inclusion in PubMed, CAS, Scopus and Google Scholar

- Research which is freely available for redistribution 